\title{
SEBARAN KANDUNGAN LOGAM BERAT Cd PADA SEDIMEN DI MUARA SUNGAI WAY KUALA BANDAR LAMPUNG
}

\author{
Diky Hidayat dan Ni Putu Inda Novita \\ Jurusan Kimia Fakultas Matematika dan Ilmu Pengetahuan Alam \\ Universitas Lampung \\ email: dhtsloblg@yahoo.co.id
}

\begin{abstract}
ABSTRAK
Penelitian penentuan penyebaran konsentrasi logam berat $\mathrm{Cd}$ pada sedimen di muara sungai Way Kuala telah dilakukan. Tujuan penelitian ini adalah untuk melihat penyebaran konsentrasi logam berat pada sedimen di muara tersebut. Konsentrasi Cd ditentukan dengan menggunakan spektrofotometer serapan atom (SSA), dengan menggunakan empat validasi metode yaitu batas deteksi, presisi, akurasi, dan linieritas. Hasil menunjukkan bahwa konsentrasi logam berat Cd dalam sampel sedimen di hulu, badan, dan hilir dari muara sungai Way Kuala berada dalam kisaran $20.73 \pm 0.18$ sampai $23.00 \pm 0.81 \mathrm{ppm}$ diatas kualitas standar sedimen (0.65 sampai $2.49 \mathrm{ppm}$ ) yang telah ditetapkan oleh National Sediment Quality Survey USEPA pada tahun 2004. Validasi metode pada penentuan logam berat $\mathrm{Cd}$ dalam sedimen menunjukkan presisi dengan nilai simpangan baku relatif lebih kecil dari 5\% (RSD <5\%); akurasi 80-120\%; batas deteksi dan koefisien korelasi pada logam Cd sebesar 0.01 dan 0.998 .
\end{abstract}

Kata kunci: distribusi logam berat, Cd, muara Way Kuala

\section{DISTRIBUTION OF HEAVY METAL Cd IN SEDIMENT OF WAY KUALA ESTUARIA BANDAR LAMPUNG}

\begin{abstract}
The determination of heavy metal cadmium concentration distributed in Sediment of Way Kuala Estuary Bandar Lampung has been conducted. The aim of the research is to determine the concentration of $\mathrm{Cd}$ which is distributed in the sediment. The concentration of Cd was determined using atomic absorption spectrophotometer (AAS). There are four validation methods in these research: limit of detection, precision, accuracy and linearity. The results showed that the concentrations of heavy metal $\mathrm{Cd}$ in sediment samples at the upper course, body and downstream in sediments of the Way Kuala Estuary is in the range of $20.73 \pm 0.18$ to $23.00 \pm 0.81 \mathrm{ppm}$. The result is at above the sediment quality standards (0.65 to $2.49 \mathrm{ppm}$ ) which has been established by National Sediment Quality Survey USEPA (2004). Validation method on the determination of heavy metals $\mathrm{Cd}$ in sediments showed that the precision has RSD values $<5 \%$; Accuracy $80-120 \%$; limit of detection and correlation coefficients for each of the metal $\mathrm{Cd}$ are 0.01 and 0.998 respectively.
\end{abstract}

Keywords: heavy metals distribution, Cd, Way Kuala estuary. 


\section{PENDAHULUAN}

Sektor industri, pengolahan dan pengelolaan merupakan sektor tertinggi yang membangun perekonomian kota Bandar Lampung yaitu sebesar 38,82\% pada tahun 2007 (BPS, 2008). Dari hasil identifikasi yang telah dilakukan oleh Wiryawan dkk, pada tahun 2002 sungai Way Kuala adalah Daerah Aliran Sungai (DAS) yang paling banyak dikelilingi oleh industri yaitu sebanyak 22 dan akan bertambah seiring dengan meningkatnya pertumbuhan penduduk kota Bandar Lampung yaitu sebesar 3,79\% per tahun (BPS, 2008). Beberapa industri di sekitar sungai Way Kuala adalah industri konstruksi (PT Darma Putra Konstruksi, PT Jaya Persada Konstruksi, PT Husada Baja), industri kimia (PT Golden Sari, PT Garuntang), industri pergudangan dan peti kemas (PT Inti Sentosa Alam Bahtera).

Mengingat sampai saat ini Bandar Lampung belum memiliki Instalasi Pengolahan Air Limbah (IPAL) terpadu, dimungkinkan bahwa limbah industri yang merupakan limbah B3 (Bahan Beracun Berbahaya) yang dihasilkan dari proses produksi dialirkan langsung ke sungai Way Kuala (Wiryawan dkk., 1999). Limbah B3 merupakan limbah yang mengandung logam berat seperti $\mathrm{Pb}$ dan $\mathrm{Cd}$. Selain limbah industri, pencemaran logam berat juga berasal dari limbah domestik seperti buangan alat elektronik rumah tangga, korosi pipa-pipa air yang mengandung $\mathrm{Pb}$ dan Cd (Connel and Miller, 1995).

Dalam penelitian yang dilakukan oleh Yudha (2007) dapat diketahui kandungan logam berat $\mathrm{Pb}$ dan $\mathrm{Cd}$ pada air sungai Way Kuala masing-masing 0,006 dan $0,002 \mathrm{ppm}$ yaitu masih di bawah ambang batas untuk mutu air kelas III (logam $\mathrm{Pb}$ 0,03 ppm dan logam $\mathrm{Cd}$ $0,01 \mathrm{ppm}$ ), namun dari data ini tidak memberikan informasi kandungan logam berat pada sedimen. Logam berat dapat terakumulasi dalam sedimen karena dapat terikat dengan senyawa organik dan anorganik, melalui proses adsorpsi dan pembentukan senyawa kompleks (Forstner and Prosi, 1978). Karena logam berat dapat terakumulasi sedimen, maka kadar logam berat pada sedimen lebih besar dari air.

Muara sungai merupakan tempat mencari makanan, bereproduksi dan tumbuh besar terutama bagi biota akuatik seperti kepiting, tiram, kerang, berbagai siput kecil serta udang (Perkins, 1974). Kehadiran logam berat $\mathrm{Pb}$ dan $\mathrm{Cd}$ pada muara sungai akan memberikan sifat toksik terhadap biota akuatik dan kesehatan manusia yang mengkonsumsinya .

Akumulasi logam berat Cd dapat menyebabkan tekanan darah tinggi, kerusakan jaringan testikular, kerusakan ginjal dan kerusakan sel-sel darah merah (Pallar 1994). Peristiwa yang dipublikasikan secara luas akibat pencemaran logam $\mathrm{Cd}$ adalah itai-itai disease di sepanjang sungai Jinzo di pulau Honsyu, Jepang (Darmono, 1995).

Dari uraian di atas, perlu dilakukan kajian sebaran logam berat $\mathrm{Cd}$ pada sedimen di muara sungai Way Kuala sehingga dapat mencerminkan tingkat pencemaran yang sesungguhnya.

\section{METODE PENELITIAN}

\section{Alat dan Bahan}

Alat-alat yang digunakan dalam penelitian ini adalah : Spektrofotometer Serapan Atom GBC X 200, eckmen grab Wildco Wildlife Supply Company, orbital shaker gallenhamp, neraca analitik, botol sampel, kertas saring, $\mathrm{pH}$ meter, termometer, mortar dan peralatan gelas yang umum digunakan di laboratorim.

Bahan-bahan yang digunakan adalah sampel sedimen, $\mathrm{HNO}_{3}$ pekat, $\mathrm{HNO}_{3} 1 \mathrm{~N}$, dan akuades. 


\section{Prosedur Penelitian}

\section{Metode Pengambilan Sampel}

a. Persiapan Pengambilan Sampel

Sebelum melakukan pengambilan sampel, semua wadah dicuci dengan sabun dan dibilas merata dengan air sampai busanya habis, kemudian dicuci dengan $\mathrm{HNO}_{3} 1 \mathrm{~N}$ untuk menghilangkan kontaminasi logam yang menempel dalam wadah sampel. Proses pengeringan dan penyimpanan dilakukan dalam keadaan tertutup sampai digunakan (Rinawati, 2009).

\section{b. Pengambilan Sampel}

Sampel sedimen diambil di bagian muara sungai pada 9 titik dengan pengulangan empat kali. Sedimen diambil dengan menggunakan eckmen grab, kemudian didinginkan sampai proses selanjutnya. Pada saat pengambilan sampel sedimen dilakukan pengukuran temperatur, $\mathrm{pH}$ dan kuat arus air.

\section{Preparasi Sampel}

Sedimen basah dikeringkan dalam oven pada suhu $110^{\circ} \mathrm{C}$ selama 3 jam kemudian digerus. Ditimbang dengan teliti $20 \mathrm{~g}$ sedimen yang telah digerus. Sedimen yang telah digerus dimasukkan ke dalam elenmeyer kemudian ditambahkan $25 \mathrm{ml}$ $\mathrm{HNO}_{3}$ pekat dan digoyangkan selama 30 menit, kemudian didiamkan selama 3 jam pada suhu ruang. Setelah didiamkan selama 3 jam ditambahkan $100 \mathrm{ml}$ akuades kemudian disaring dengan menggunakan kertas saring. Sisa sedimen pada kertas saring dicuci dengan $10 \mathrm{ml}$ akuades sebanyak lima kali pengulangan sampai $\mathrm{pH}$ berkisar 2-3. Filtrat yang dihasilkan kemudian dianalisis dengan Spektrofotometer Serapan Atom GBC X 200.

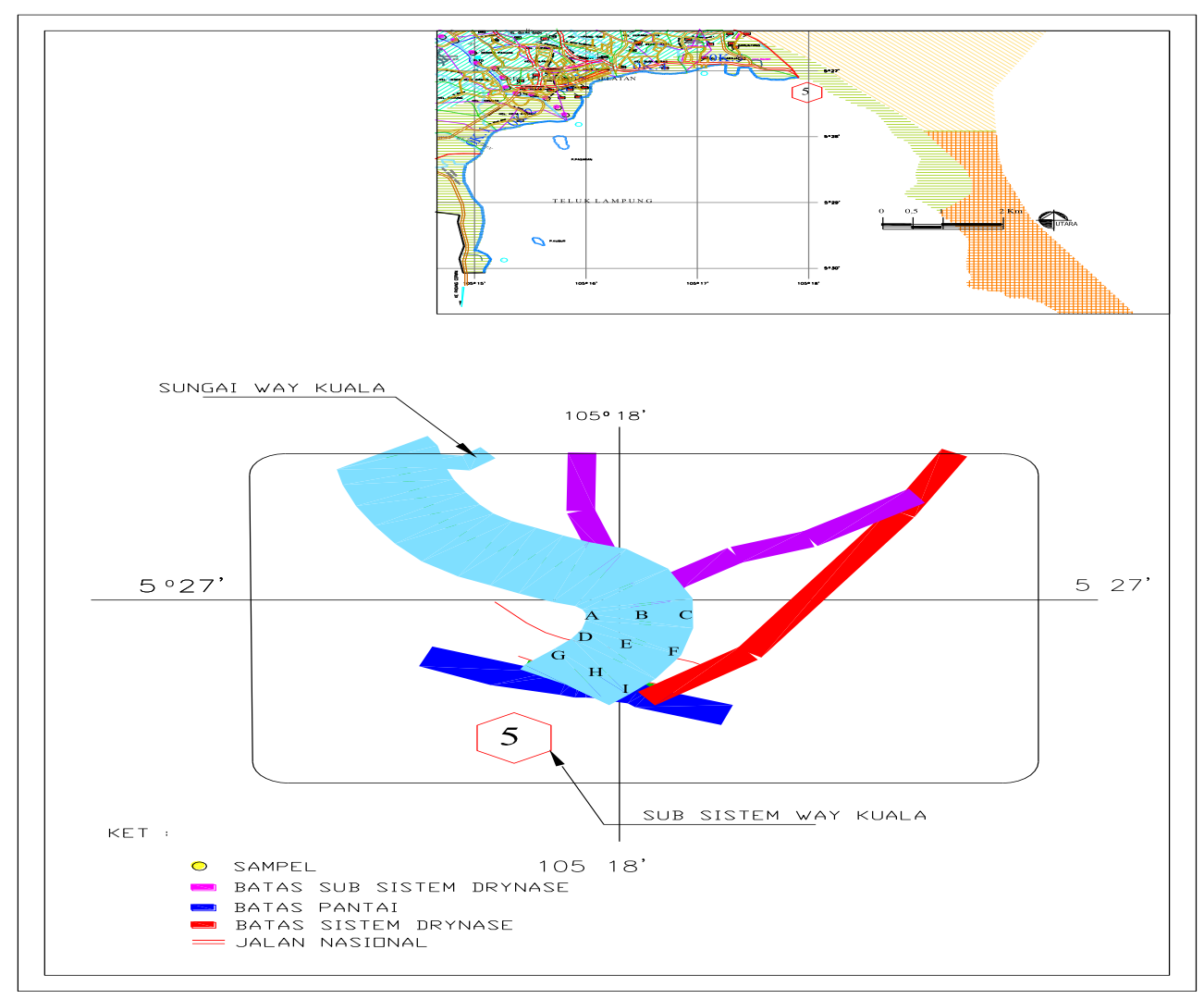

Gambar 1. Lokasi Pengambilan Sampel 


\section{Penentuan konsentrasi Cd pada sedimen dengan spektrofotometer serapan Atom (SSA)}

Penentuan konsentrasi logam Cd pada sampel dilakukan dengan teknik kurva kalibrasi. Masing-masing konsentrasi standar, serapannya diukur dengan Spektrofotometer Serapan Atom GBC X 200 pada kondisi optimum yang didapat dari manual alat. Dari grafik kurva standar terdapat korelasi antara Konsentrasi (x) dengan Absorbansi (y). Dengan menggunakan persamaan regresi linier maka konsentrasi dari sampel dapat diketahui:

$$
y=a+b x
$$

Keterangan :

$$
\begin{aligned}
& \text { y : Absorbansi Sampel } \\
& \mathrm{b}: \text { Slope } \\
& \mathrm{x}: \text { Konsentrasi sampel } \\
& \mathrm{a}: \text { Intersep }
\end{aligned}
$$

Setelah konsentrasi pengukuran diketahui, maka konsentrasi sebenarnya dari $\mathrm{Cd}$ dalam sampel kering dapat ditentukan dengan persamaan berikut (Christian, 1994) :

$$
\mathrm{M}=\frac{\mathrm{C}_{\mathrm{reg}} \cdot \mathrm{V} \cdot \mathrm{F}}{\mathrm{B}}
$$

Keterangan :

M :Konsentrasi logam dalam sampel $(\mathrm{mg} / \mathrm{Kg})$

$\mathrm{C}_{\text {reg }} \quad$ : konsentrasi yang diperoleh dari

kurva kalibrasi (mg/L)

$\mathrm{V}$ : Volume larutan sampel (mL)

B : Bobot sampel (g)

F : Faktor Pengenceran

\section{Validasi Metode}

Penelitian mengenai Kajian Sebaran Logam Berat Cd pada sedimen di Muara Sungai Way Kuala Bandar Lampung menggunakan 3 validasi metode yaitu limit deteksi, presisi dan kecermatan

a. Limit Deteksi
Pada penelitian ini batas deteksi ditentukan dengan mengukur respon blanko sebanyak 5 kali dan dihitung simpangan baku respon blanko.

\section{b. Presisi (ketelitian)}

Penentuan presisi dilakukan dengan mengukur konsentrasi sampel dengan 4 kali pengulangan. Dari nilai absorbansi tersebut kemudian ditentukan nilai konsentrasi (persamaan regresi larutan standar), lalu nilai simpangan baku (SD) dan simpangan baku relatif (RSD) dapat ditentukan. Metode dengan presisi yang baik ditunjukan dengan perolehan simpangan baku relatif (RSD) $<5 \%$ (Christian, 1994).

\section{c. Kecermatan (Akurasi)}

Kecermatan dinyatakan sebagai persen perolehan kembali (recovery) analit yang ditambahkan. Pada penelitian ini, persen perolehan kembali ditentukan dengan cara menambahkan larutan standar pada larutan sampel untuk ditentukan absorbansinya kemudian dibandingkan dengan blanko (tanpa penambahan larutan standar). Masing-masing konsentrasi larutan standar yang ditambahkan ke dalam sampel adalah 20 ppm untuk logam $\mathrm{Cd}$.

\section{HASIL DAN PEMBAHASAN}

Pencemaran perairan merupakan masalah lingkungan hidup yang perlu dipantau sumber dan dampaknya terhadap ekosistem. Salah satu indikator terjadinya pencemaran pada lingkungan adalah analisis logam pada sampel sedimen.

Hasil analisis logam $\mathrm{Cd}$ pada sedimen di muara sungai Way Kuala dapat dilihat pada Tabel 1, bahwa sebaran logam $\mathrm{Cd}$ terdapat pada semua titik pengambilan sampel sedimen $(\mathrm{A}, \mathrm{B}, \mathrm{C}$, D, E, F, G, H, I) dengan konsentrasi yang tinggi. Sebaran logam Cd pada muara 
sungai Way Kuala memiliki konsentrasi yang hampir merata yaitu pada bagian hulu muara sungai $(\mathrm{A}, \mathrm{B}, \mathrm{C}) 21,22 \pm 0,13$ ppm, badan muara sungai (D, E, F) 22,24 $\pm 0,34 \mathrm{ppm}$ dan hilir muara sungai $(\mathrm{G}$, H, I) 22,72 $\pm 0,43$ ppm.

Tabel 1, menunjukka konsentrasi logam Cd pada sedimen di hulu, badan dan hilir muara sungai Way Kuala masing-masing adalah $21,22 \pm 0,13$; $22,24 \pm 0,34$ dan 22,72 $\pm 0,43 \mathrm{ppm}$ berada di atas baku mutu yang telah ditetapkan oleh National Sediment Quality Survey USEPA (2004) yaitu pada rentang 0,65-2,49 ppm.

Tingginya kandungan logam $\mathrm{Cd}$ pada sedimen disebabkan karena muara sungai Way Kuala dekat dengan saluran pembuangan besar limbah rumah tangga dan industri di Bandar lampung. Serta di dekat hilir muara sungai Way Kuala terdapat aktivitas pelabuhan, di mana terdapat banyak kapal para nelayan. Kapal-kapal tersebut banyak dilapisi oleh logam $\mathrm{Cd}$ untuk memperlambat proses korosi. Pada periode tertentu, kapalkapal tersebut akan mengalami korosi sehingga logam $\mathrm{Cd}$ akan terlarut dalam perairan. Dengan pengaruh arus laut yang mengarah ke muara sungai Way kuala, maka logam tersebut akan diangkut ke muara sungai. Dengan bertemunya arus dari sungai dan arus dari laut menyebabkan turbulensi di daerah muara sehingga konsentrasi logam $\mathrm{Cd}$ pada muara lebih tinggi dibandingkan di sungai.

Dalam penelitian yang dilakukan oleh Yudha (2007) dapat diketahui kandungan logam berat $\mathrm{Cd}$ pada air sungai Way Kuala 0,002 ppm berada di bawah baku mutu air kelas III $(0,01$ ppm). Hal ini menunjukan bahwa logam berat dari berbagai sumber pencemar yang masuk ke muara sungai telah mengalami proses pengendapan. Muara sungai daerahnya lebih rendah dibandungkan dengan hulu dan badan sungai, sehingga sedimentasi cenderung lebih cepat pada muara sungai yang menyebabkan konsentrasi logam Cd pada sedimen di muara sungai Way Kuala lebih tinggi dibandingkan dengan konsentrasi logam $\mathrm{Cd}$ pada air sungai Way kuala.

Berdasarkan hasil analisis logam Cd pada sedimen (Tabel 2.), diketahui bahwa simpangan baku relatif (RSD) untuk logam $\mathrm{Cd}$ semua titik memiliki nilai RSD dibawah $5 \%$ yaitu pada rentang (0,36-2,22 \%). Nilai RSD tersebut tergolong baik, karena RSD yang baik berada di bawah $5 \%$ dengan tingkat kepercayaannya sebesar $95 \%$ (Christian, 1994).

Tabel 1. Sebaran Logam Cd padaSedimen

\begin{tabular}{|c|c|c|c|c|c|}
\hline No & $\begin{array}{c}\text { Titik } \\
\text { Pengambilan } \\
\text { Sampel }\end{array}$ & $\begin{array}{c}\overline{\mathrm{M}} \\
(\mathbf{p p m})\end{array}$ & $\begin{array}{c}\text { SD } \\
(\mathbf{p p m})\end{array}$ & $\begin{array}{c}\overline{\mathrm{M}} \pm \mathrm{SD} \\
(\mathbf{p p m})\end{array}$ & $\begin{array}{c}\overline{\mathrm{M}} \pm \mathrm{SD} \\
(\mathbf{p p m})\end{array}$ \\
\hline 1 & $\mathrm{~A}$ & 20,73 & 0,12 & $20,73 \pm 0,12$ & \multirow{3}{*}{$\begin{array}{c}21,22 \pm \\
0,13\end{array}$} \\
\hline 2 & B & 22,2 & 0,09 & $22,20 \pm 0,09$ & \\
\hline 3 & $\mathrm{C}$ & 20,73 & 0,18 & $20,73 \pm 0,18$ & \\
\hline 4 & $\mathrm{D}$ & 21,79 & 0,07 & $21,79 \pm 0,07$ & \multirow{3}{*}{$\begin{array}{c}22,24 \pm \\
0,34\end{array}$} \\
\hline 5 & $E$ & 23,00 & 0,81 & $23,00 \pm 0,81$ & \\
\hline 6 & $\mathrm{~F}$ & 21,79 & 0,14 & $21,79 \pm 0,14$ & \\
\hline 7 & $\mathrm{G}$ & 22,58 & 0,41 & $22,58 \pm 0,41$ & \multirow{3}{*}{$\begin{array}{c}22,72 \pm \\
0,43\end{array}$} \\
\hline 8 & $\mathrm{H}$ & 22,94 & 0,37 & $22,94 \pm 0,37$ & \\
\hline 9 & I & 22,65 & 0,50 & $22,65 \pm 0,50$ & \\
\hline
\end{tabular}


Tabel 2. Nilai SD dan RSD hasil analisis logam Cd pada sedimen

\begin{tabular}{|c|c|c|}
\hline $\begin{array}{c}\text { Lokasi } \\
\text { pengambilan } \\
\text { Sampel }\end{array}$ & $\begin{array}{c}\text { SD } \\
\text { Cd }\end{array}$ & $\begin{array}{c}\text { RSD (\%) } \\
\text { Logam } \\
\text { Cd }\end{array}$ \\
\hline A & 0,12 & 0,60 \\
\hline B & 0,09 & 0,90 \\
\hline C & 0,18 & 0,36 \\
\hline D & 0,07 & 0,36 \\
\hline E & 0,81 & 0,53 \\
\hline F & 0,14 & 0,64 \\
\hline G & 0,41 & 1,83 \\
\hline H & 0,37 & 1,6 \\
\hline I & 0,50 & 2,22 \\
\hline
\end{tabular}

Untuk mengukur ketepatan hasil dari analisis yang telah dilakukan, dalam hal ini perlu dilakukan uji perolehan kembali. Pada penelitian ini, persen perolehan kembali (Recovery) ditentukan dengan menambahkan larutan standar pada masing-masing titik pengambilan sampel dengan satu kali pengulangan.

Tabel 3. Persen perolehan kembali (Recovary) logam Cd

\begin{tabular}{|c|c|}
\hline $\begin{array}{c}\text { Titik } \\
\text { pengambilan } \\
\text { Sampel }\end{array}$ & $\begin{array}{c}\text { Persen perolehan } \\
\text { kembali (\%) } \\
\text { Logam Cd }\end{array}$ \\
\hline A & 100,4541 \\
\hline B & 99,9091 \\
\hline C & 99,9091 \\
\hline D & 100,000 \\
\hline E & 99,9091 \\
\hline F & 100,0000 \\
\hline G & 99,8183 \\
\hline H & 99,9091 \\
\hline I & 99,3642 \\
\hline
\end{tabular}

Berdasarkan hasil analisis logam Cd pada sedimen di muara sungai Way Kuala seperti pada Tabel 3, dapat dilihat bahwa persen perolehan secara umum baik yaitu berada pada rentang $80-120 \%$. Nilai persen perolehan kembali (Recovery) tersebut tergolong baik, karena menurut Harmita (2004) syarat persen perolehan kembali yang paling baik adalah antara 80-120\%.

Berdasarkan hasil analisis larutan standar dengan menggunakan spektofotometer serapan atom diperoleh persamaan garis regresi Cd (Gambar 2.) yaitu $\mathrm{y}=1,101 \mathrm{x}-0,081$ dan hasil kofisien korelasinya adalah 0,998 mendekati 1 sehingga metode ini dapat digunakan untuk analisis logam $\mathrm{Cd}$ dengan hasil yang baik. Kriteria penerimaan untuk koefisien korelasi berdasarkan Harmita (2004) adalah >0,9950; sehingga koefisien korelasi untuk logam Cd pada penelitian ini termasuk baik. Nilai koefisien korelasi $\mathrm{Cd}$ adalah 0,998, nilai ini menunjukan bahwa grafik regresi larutan standar memiliki keakuratan 99,8\% dalam menentukan konsentrasi logam Cd.

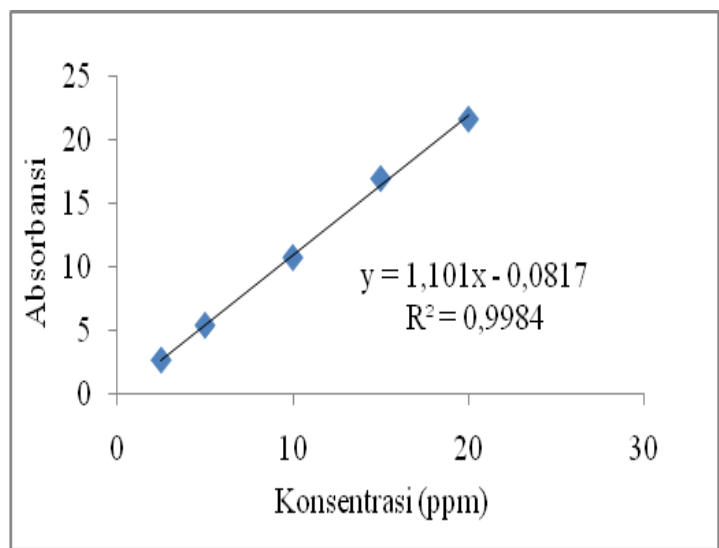

Gambar 2. Grafik Regresi Larutan Standar Cd

\section{KESIMPULAN DAN SARAN}

Konsentrasi logam berat $\mathrm{Cd}$ pada sampel sedimen di muara sungai Way Kuala Bandar Lampung yaitu pada rentang 20,73 $\pm 0,18$ sampai 23,00 \pm 0,81 ppm berada di atas baku mutu sedimen $(0,65$ - 2,49 ppm) yang telah ditetapkan oleh National Sediment Quality Survey USEPA (2004).

Berdasarkan hasil pembahasan, maka penulis dapat memberikan saran yaitu untuk mengetahui tingkat pencemaran 
lebih lanjut perlu dilakukan analisis logam berat lain maupun kandungannya pada organisme di muara Sungai Way Kuala Bandar Lampung.

\section{UCAPAN TERIMA KASIH}

Ucapan Terima Kasih penulis haturkan kepada CV Kejayaan 741 dan Lembaga Penelitian Unila yang telah membantu pendanaan penelitian ini.

\section{DAFTAR PUSTAKA}

BPS, 2008, Lampung Dalam Angka, Badan Pusat Statistik, Provinsi Lampung.

Christian, D., Gary, 1994, Analitical Chemistry, John Wiley and Sons inc, New York.

Connel, D.W., \& G.J., Miller, 1983, Kimia dan Ekotoksikologi Pencemaran, Terjemahan Yanti Koestoer, 1995, Universitas Indonesia Press, Jakarta.

Darmono, 1995, Logam dalam Sistem Biologi Makhluk Hidup, Universitas Indonesia Pres, Jakarta.

Fortstner, U. \& F., Prosi, 1987, Proceeding of Course Held at The Joint Research centre of The Commission of Europian Commities, Ispra Pargamon Press, Oxford.

Harmita, 2004, Petunjuk Pelaksanaan Validasi Metode dan Cara Perhitungannya, Departemen Farmasi FMIPA-UI, Jakarta.

Palar, H., 1994, Pencemaran dan Toksikologi Logam Berat, Rineka Cipta, Jakarta.

Perkins, E.J., 1974, The Biology of Estuaries and Coastal Waters, Academic Press, London.
Rinawati, 2009, Analisis Simultan Logam Berat $\mathrm{Pb}, \mathrm{Cu}, \mathrm{Zn}, \mathrm{Cr}, \mathrm{Mn}$, $\mathrm{Ni}$, Fe dan $\mathrm{Cd}$ Pada Bioindikator Remis (Eremopyrgus eganensis) di Sungai Kuripan Lampung Menggunakan ICP-OES, Prosiding SATEK II Universitas Lampung, Bandar Lampung, 234-241

USEPA, 2004, The Incidence and Severity of Sediment Contamination in Surface Waters of United States, National Sediment Quality Survey: $2^{\text {nd }}$ Edition. $\quad$ EPA-823-R-04-2007. U. S. Enviromental Protection Agency, Washington D.C.

Wiryawan, B., B., Marsden, H.A., Susanto, A.K., Mahi, M., Ahmad, \& H., Poespitasari, 2002, Rencana Strategis Pengelolaan Wilayah Pesisir Lampung, PKSPL IPB, Bandar Lampung.

Wiryawan, B., B. Marsden, H.A. Susanto, A.K. Mahi, M. Ahmad \& H. Poespitasari (Editor), 1999, Atlas Sumberdaya Wilayah Pesisir Lampung, Kerjasama PEMDA Propinsi Lampung dengan Proyek Pesisir (Coastal Resources Center, University of Rhode Island dan Pusat Kajian Sumberdaya Pesisir dan Lautan, Institut Pertanian Bogor), Bandar Lampung. Indonesia, 109.

Yudha, I.G., 2007, Kajian Pencemaran Logam Berat $\mathrm{Pb}$ dan $\mathrm{Cd}$ di Wilayah Pesisir Kota Bandar Lampung, Jurnal Lingkungan. Pusat Studi Lingkungan Universitas Lampung. Bandar Lampung, Vol.12, No. 6, 12-19. 